\title{
Sildenafil Ameliorates Advanced Glycation End Products-Induced Mitochondrial Dysfunction in HT-22 Hippocampal Neuronal Cells
}

\author{
Soon Ki Sung, M.D., ${ }^{1,2}$ Jae Suk Woo, M.D., ${ }^{3}$ Young Ha Kim, M.D., ${ }^{1}$ Dong Wuk Son, M.D., ${ }^{1,2}$ Sang Weon Lee, M.D., ${ }^{1}$ Geun Sung Song, M.D. \\ Departments of Neurosurgery, ${ }^{1}$ Physiology, ${ }^{3}$ Pusan National University School of Medicine, Busan, Korea \\ Research Institute for Convergence of Biomedical Science and Technology, ${ }^{2}$ Pusan National University Yangsan Hospital, Busan, Korea
}

Objective : Accumulation of advanced glycation end-products (AGE) and mitochondrial glycation is importantly implicated in the pathological changes of the brain associated with diabetic complications, Alzheimer disease, and aging. The present study was undertaken to determine whether sildenafil, a type 5 phosphodiesterase type (PDE-5) inhibitor, has beneficial effect on neuronal cells challenged with AGE-induced oxidative stress to preserve their mitochondrial functional integrity.

Methods : HT-22 hippocampal neuronal cells were exposed to AGE and changes in the mitochondrial functional parameters were determined. Pretreatment of cells with sildenafil effectively ameliorated these AGE-induced deterioration of mitochondrial functional integrity.

Results : AGE-treated cells lost their mitochondrial functional integrity which was estimated by their MTT reduction ability and intracellular ATP concentration. These cells exhibited stimulated generation of reactive oxygen species (ROS), disruption of mitochondrial membrane potential, induction of mitochondrial permeability transition, and release of the cytochrome $\mathrm{C}$, activation of the caspase- 3 accompanied by apoptosis. Western blot analyses and qRT-PCR demonstrated that sildenafil increased the expression level of the heme oxygenase-1 (HO-1). CoPP and bilirubin, an inducer of HO-1 and a metabolic product of HO-1, respectively, provided a similar protective effects. On the contrary, the H0-1 inhibitor ZnPP IX blocked the effect of sildenafil. Transfection with HO-1 siRNA significantly reduced the protective effect of sildenafil on the loss of MTT reduction ability and MPT induction in AGE-treated cells.

Conclusion : Taken together, our results suggested that sildenafil provides beneficial effect to protect the HT-22 hippocampal neuronal cells against AGE-induced deterioration of mitochondrial integrity, and upregulation of $\mathrm{HO}-1$ is involved in the underlying mechanism.

Key Words : Sildenafil $\cdot$ Glycation end products, advanced $\cdot$ Mitochondria $\cdot$ Hippocampus.

\section{INTRODUCTION}

Diabetes mellitus (DM) has become a major health problem affecting the global population. It has been anticipated that diabetic population will increase by $42 \%$ in the developed countries and by $170 \%$ in the developing countries by $2030{ }^{15}$.

Patients with DM suffer various complications, such as vasculopathy, retinopathy, nephropathy, and peripheral neuropathy. Mounting evidences have indicated that DM is also implicated in the brain pathological changes, named as the diabetic encephalopathy, which is a complication of DM in the central nervous system (CNS). It is characterized by cognitive deficits and neuropathology ${ }^{19,25,43)}$.

Although prolonged exposure to hyperglycemia is considered to be a major pathophysiological factor in the development of diabetic complications, the associated mechanisms are not fully understood yet. Several major pathways are involved in the development and progression of diabetic complications. These include polyol pathway ${ }^{31)}$, mitogen-activated protein kinases ${ }^{35)}$, poly-ADP ribose polymerase ${ }^{28)}$, cyclooxygenase- $2^{33)}$, and advanced glycation end-products ${ }^{40)}$.

Advanced glycation end-products (AGE) are produced through non-enzymatic addition of carbohydrates to proteins. It makes cells more subject to damage and premature aging ${ }^{5)}$. Accelerated formation and accumulation of AGE has been suggested to play a pivotal role in various metabolic disorders including diabetes $^{45)}$, obesity ${ }^{12)}$, metabolic syndromes ${ }^{32)}$.

It is now well established that mitochondrial glycation is im-

- Received : November 30, 2015 • Revised : December 11, 2015 • Accepted : January 30, 2016

- Address for reprints : Geun Sung Song, M.D.

Department of Neurosurgery, Pusan National University School of Medicine, 20 Geumo-ro, Mulgeum-eup, Yangsan 50612, Korea

Tel : +82-55-360-2126, Fax : +82-55-360-2156, E-mail : gnsong@pusan.ac.kr

- This is an Open Access article distributed under the terms of the Creative Commons Attribution Non-Commercial License (http://creativecommons.org/licenses/by-nc/3.0) which permits unrestricted non-commercial use, distribution, and reproduction in any medium, provided the original work is properly cited. 
portantly implicated in the pathological changes associated with diabetic complications and aging ${ }^{34)}$. The mitochondria are the major intracellular site responsible for the reactive oxygen species (ROS) production ${ }^{39,46}$. Excess ROS production under oxidative stress can cause deterioration of functional and structural integrity of the mitochondria, which leads to depletion of cellular ATP, release of mitochondrial cytochrome $\mathrm{C}$, and finally cell death $^{21}$. Therefore, mitochondria should be considered as the first target site for studying harmful effects in AGE-mediated neurotoxicity.

Sildenafil is a specific inhibitor of phosphodiesterase type 5 (PDE-5), it exerts its pharmacological effects by suppressing the breakdown of cGMP ${ }^{13)}$. At first, it attracted investigator's attention for the possible antihypertensive and antianginal drug ${ }^{38)}$. Later, it evolved into a new-line oral treatment for erectile dysfunction $^{16)}$. It has been acknowledged as an effective treatment for pulmonary arterial hypertension ${ }^{13)}$.

The potential application of sildenafil in many experimental models of diseases has been indicated in addition to erectile dysfunction and pulmonary hypertension. Pretreatment of sildenafil attenuated ischemia-reperfusion renal injury in rats ${ }^{10)}$. It also attenuated lung and kidney injury due to overproduction of oxidant activity in a rat model of sepsis ${ }^{7}$. Together with these observations several evidences suggested that the therapeutic action of sildenafil may be mediated partly through antioxidant mechanisms ${ }^{14,17,27)}$.

The present study was undertaken to determine whether sildenafil has beneficial effect on neuronal cells challenged with AGE-induced oxidative stress to preserve the mitochondrial functional integrity.

\section{MATERIALS AND METHODS}

\section{Cell culture}

HT-22 cells (Salk Institute, San Diego, CA, USA) were routinely grown in $75 \mathrm{~cm}^{2}$ culture flasks with Dulbecco's Modified Eagle's Medium (DMEM) supplemented with fetal bovine serum (10\%), penicillin $\mathrm{G}(150 \mathrm{IU} / \mathrm{mL})$ and streptomycin $(50 \mu \mathrm{g} /$ $\mathrm{mL}$ ). When reaching confluency, cells were trypsinized using $0.05 \%$ trypsin/0.53 mM EDTA solution and reseeded at onefifth the initial density. For the experiments cells were seeded into the appropriate culture dishes, such as 24 to 96 -well plates or on collagen-coated cover glasses in 6-well plates depending on the respective experiments.

\section{Preparation of AGE-BSA}

Glycer-AGE was prepared as previously described ${ }^{9)}$. Endotoxin-free bovine serum albumin (BSA, $10 \mathrm{mg} / \mathrm{mL}$ ) was incubated with $100 \mathrm{mM}$ D-glyceraldehyde in phosphate buffer $(0.2 \mathrm{M}$, $\mathrm{pH}$ 7.4). The reaction mixture was filtered through microporous membrane filter $(0.22 \mu \mathrm{m}$ pore size $)$ and then incubated for 7 days in the dark at $37^{\circ} \mathrm{C}$. Low molecular reactants and unincorporated D-glyceraldehyde were removed by dialysis against 0.1
M phosphate buffer overnight at $4^{\circ} \mathrm{C}$. BSA incubated at the same conditions in phosphate buffer without D-glyceraldehyde was used as BSA control. Every AGE preparation was tested for endotoxin by the limulus amebocytelysate assay, and stored at $4^{\circ} \mathrm{C}$.

\section{Assay of mitochondrial MTT reduction ability}

After exposure to experimental protocols, the cells were incubated with $50 \mu \mathrm{L}$ of $5 \mathrm{mg} / \mathrm{mL}$ 3-(4,5-dimethyl-2-thiazyl)-2,5diphenyl-2H-tetrazolium bromide (MTT) at $37^{\circ} \mathrm{C}$ for $4 \mathrm{hr}$. The absorbance value proportional to the formation of formazan from MTT was determined at $540 \mathrm{~nm}$ using automatic multiwell spectrophotometer $^{26)}$. MTT reduction values were expressed as percentage of the BSA-control cells.

\section{Measurement of ATP content}

ATP levels were measured in cells with a luciferin-luciferase assay $^{23)}$. After exposure to experimental procedures, cells were solubilized with $500 \mu \mathrm{L}$ of $0.5 \%$ Triton X-100 and acidified with $100 \mu \mathrm{L}$ of $0.6 \mathrm{M}$ perchloric acid and placed on ice. Cell suspension was then diluted with $10 \mathrm{mM}$ potassium glutamate buffer containing $4 \mathrm{mM} \mathrm{MgSO}_{4}$ (pH 7.4), and $100 \mu \mathrm{L}$ of $20 \mathrm{mg} / \mathrm{mL}$ luciferin-luciferase was added to $10 \mu \mathrm{L}$ of diluted sample. Light emission was recorded at $20 \mathrm{sec}$ with a luminometer (MicroLumat LB96P, Berthold, Germany). Protein content was determined on a portion of the cell sample using Biorad protein assay kit.

\section{Analysis of ROS production}

Intracellular production of reactive oxygen species (ROS) was determined using DCFH-DA. Cells were preincubated with 10 $\mu \mathrm{M}$ DCFH-DA for $1 \mathrm{hr}$ at $37^{\circ} \mathrm{C}$, and then exposed to experimental procedures for various durations. DCF fluorescence was analysed using FACSort Flow Cytometer (Becton-Dickinson Bioscience, San Jose, CA, USA).

\section{Measurement of mitochondrial membrane potential}

Mitochondrial transmembrane potential was measured with $\mathrm{DiOC}_{6}(3)$. Reduction in $\mathrm{DiOC}_{6}(3)$ staining indicates reduction of the mitochondrial transmembrane potential. Cells were loaded with $\operatorname{DiOC}_{6}(3)$ at a final concentration of $50 \mathrm{nM}$ for $20 \mathrm{~min}$ at $37^{\circ} \mathrm{C}$ in the dark. Cells were washed and resuspended in PBS. The fluorescence intensity was analyzed with a FACsort Becton Dickinson Flow Cytometer (Beckton-Dickinson Bioscience, San Jose, CA, USA).

\section{Detection of mitochondrial permeability transition}

To determine the formation of mitochondrial permeability transition (MPT) pore, a double staining method with fluorescent dyes, calcein/AM and TMRM was used as described by Lemasters et al. ${ }^{21)}$.

\section{Analysis of cytochrome $\mathrm{C}$ release}

The amount of cytochrome $\mathrm{C}$ released from the mitochondrial intermembrane space into the cytosol was determined by a 
western blot analysis. After washing with ice-cold phosphatebuffered saline, cells were resuspended in permeabilization buffer containing $75 \mathrm{mM} \mathrm{NaCl}, 1 \mathrm{mM} \mathrm{NaH} \mathrm{PO}_{4}, 8 \mathrm{mM} \mathrm{Na}_{2} \mathrm{PO}_{4}$, $250 \mathrm{mM}$ sucrose, $1 \mathrm{mM}$ phenylmethylsulfonyl fluoride, additional protease inhibitors, and $0.05 \%$ digitonin. Following centrifugation at $15000 \mathrm{rpm}$ at $4^{\circ} \mathrm{C}$ for $10 \mathrm{~min}$, the supernatant was separated from the pellet consisting of mitochondria and cellular debris. Equal amounts of protein were loaded on a 15\% acrylamide gel and separated by SDS-PAGE. Nitrocellulose paper was then blocked with $0.5 \%$ nonfat dry milk, probed with 0.5 $\mu \mathrm{g} / \mathrm{mL}$ polyclonal anti-cytochrome C antibodies $(1: 200$, Santa Cruz Biotechnology, Dalas, TX, USA), then with secondary antibodies (rabbit) diluted $1: 5000$. Immunoblots were developed with ECL-plus reagents from Amersham according to the manufacturer's instructions.

\section{Determination of caspase-3 activities}

A quantitative enzymatic activity assay was carried out according to instructions of the R\&D (Minneapolis, MN, USA) colorimetric assay kit manufacturer.

\section{Analysis of apoptosis}

Apoptosis was analyzed by staining with Hoechst-33258. For fluorescence microscopy, cells were grown on cover glasses. After exposure to experimental procedures, cells were fixed by $4 \%$ paraformaldehyde and loaded for $30 \mathrm{~min}$ at $37^{\circ} \mathrm{C}$ with $5 \mu \mathrm{M}$ Hoechst-33258 in HBSS. After washout, cover glasses were mounted on the slide glasses with PBS : Glycerol=1 : 1 solution. Apoptotic cells with condensed or fragmented nuclei were examined using a fluorescence microscopy.

\section{Real-time reverse-transcriptase polymerase chain reaction}

Total RNA was prepared using Trizol reagent (Invitrogen, Carlsbad, CA, USA). RNA concentration was determined by spectrometry. Quantitative real-time PCR was performed with SYBR Green Mastermix (Invitrogen, Carlsbad, CA, USA) and 15 pmol primers for mouse HO- 1 , and $\beta$-actin. Reactions were performed in triplicate and specificity was monitored using melting curve analysis after cycling. Primers used were 5'-GGT GATGGCTTCCTTGTACC-3' (forward) and 5'-AGTGAG GCCCATACCAGAAG-3' (reverse) for HO-1, and 5'-AGAG GGAAATCGTGCGTGAC-3' (forward) and 5'-CAATAGT GATGACCTGGCCGT-3' (reverse) for $\beta$-actin.

\section{Analysis of $\mathrm{H0}-1$ protein}

Western blot analysis was performed to determine the HO-1 protein. Total intracellular protein was isolated by 5 times repeated freeze-thaw lysis in a buffer containing $\mathrm{KCl}(600 \mathrm{mM})$, Tris-Cl (20 mM), glycerol (20\%), Pefabloc (0.4 mg/mL), leupeptin $(10 \mu \mathrm{g} / \mathrm{mL})$, pepstatin $(10 \mu \mathrm{g} / \mathrm{mL})$, aprotinin $(5 \mu \mathrm{g} / \mathrm{mL})$, and $\mathrm{pH}$ 7.8. Protein content was measured by Bradford assay (Bio-Rad Laboratory, Hercules, CA, USA).

Protein samples $(40 \mu \mathrm{g})$ were electrophoresed on sodium do- decyl sulfate-polyacrylamide ( $10 \%$ gel) and transferred to immobile polyvinylidene difluoride membranes (Millipore, Bedford, MA, USA). The membranes were then blocked with 5\% skim milk in Tris-buffered saline containing 0.5\% Tween-20 (TBST) for $1 \mathrm{hr}$ at room temperature. Then the membranes were incubated with primary antibodies for HO-1 (StressGen Biotechnology, CA, USA) and $\beta$-actin (Gentest). The membranes were washed three times with TBST, and incubated with goat antimouse IgG-horseradish peroxidase with a $1: 5000$ dilution in TBST for $2 \mathrm{hr}$ at room temperature. The membranes were washed three times for $10 \mathrm{~min}$ with TBS-T again and immunolabeling was visualized using enhanced chemiluminescent HRP substrate (ECL) detection method.

\section{Transfection with H0-1 siRNA}

Transient transfection with siRNA and scrambled siRNA against human HO-1 (Santa Cruz Biotechnology, Dalas, TX, USA) were performed using the Superfect ${ }^{\circledR}$ transfection reagent (Qiagen, Hilden, Germany).

\section{Data analysis}

The data were presented as the means \pm standard error. Statistical analyses between two groups were performed by unpaired Student's t-test. Differences among groups were tested by oneway analysis of variance (ANOVA) followed by the Tukey's test. The $p$ value less than 0.05 was accepted to be statistically significant.

\section{RESULTS}

\section{Effect of sildenafil on AGE-induced mitochondrial dysfunction}

In order to determine AGE-induced changes of mitochondrial functional integrity and the effect of sildenafil, MTT reduction ability was examined. There was a time-dependent decrease in the MTT reduction ability in AGE-treated cells. The effect of AGE was dose dependent in the range from 25 to 400 $\mu \mathrm{g} / \mathrm{mL}$ (data not shown). Unless otherwise indicated in this study, we treated the cells with $200 \mu \mathrm{g} / \mathrm{mL}$ AGE for $48 \mathrm{hr}$.

The effect of anti-RAGE antibody was examined to evaluate whether the effect of AGE is ascribed to the interaction with its receptor, RAGE. In cells pretreated with anti-RAGE antibody (1 $\mu \mathrm{g} / \mathrm{mL}$ ) before exposure to AGE, AGE failed to inhibit MTT reduction ability suggesting that interaction with RAGE is crucial for the cellular actions of AGE (Fig. 1A).

In the presence of sildenafil (as sildenafil citrate, $20 \mu \mathrm{M}$ ), the AGE-induced decrease of MTT reduction ability was significantly attenuated. In the presence of an inactive cell-permeable cGMP analogue Rp-8-Br-cGMP the protective effect of sildenafil was significantly diminished, suggesting that sildenafil exerts its protective effect via a mechanism dependent on cGMP and/or cGMP-dependent protein kinases (PKG) (Fig. 1B).

As ATP is generated primarily by mitochondria through oxidative phosphorylation, intracellular ATP level is another indi- 

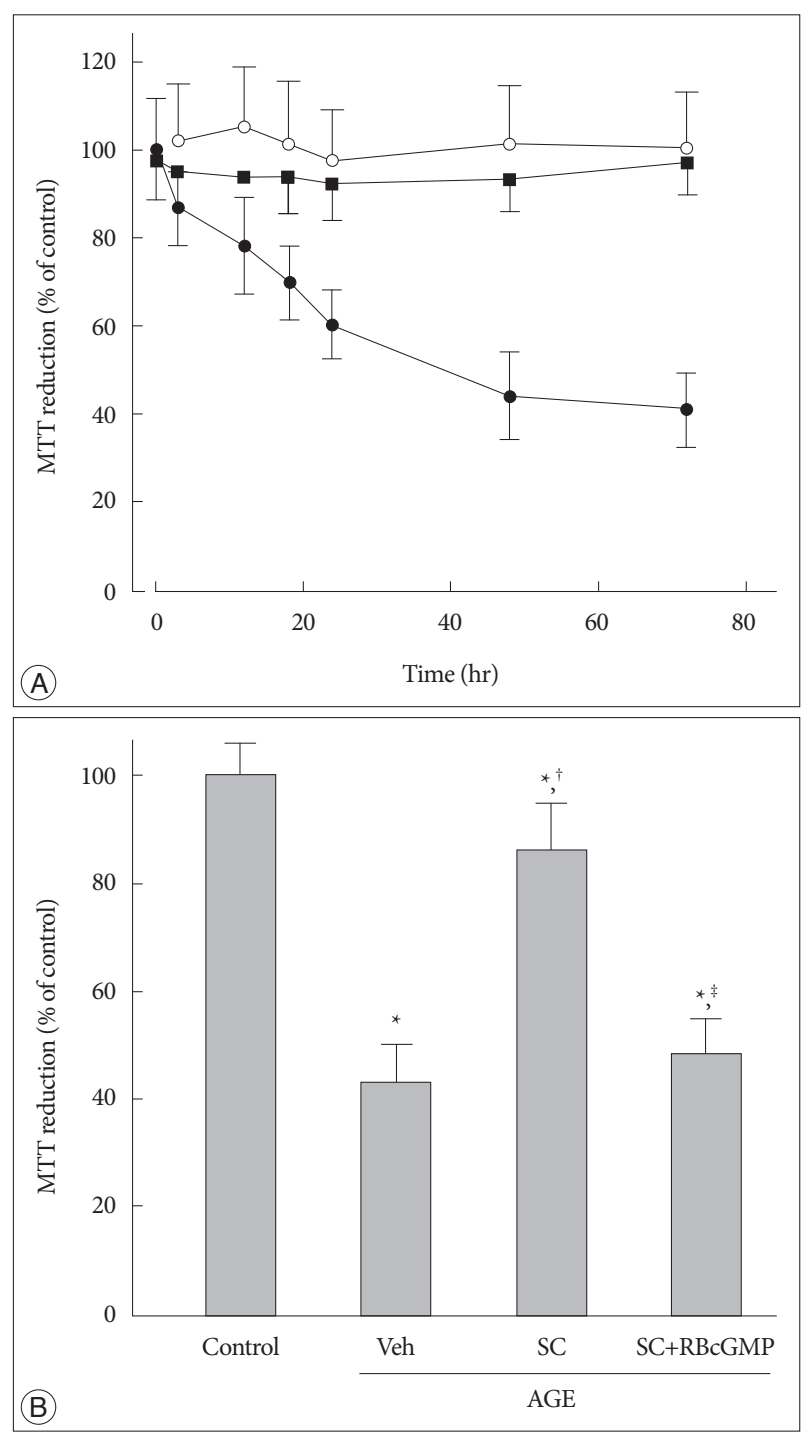

Fig. 1. Effect of sildenafil on MTT reduction ability in AGE-treated cells. A : Cells were incubated for indicated time periods in control media with BSA (open circle), in the presence of AGE alone (200 $\mu \mathrm{g} / \mathrm{mL}$, solid circle), or AGE with anti-RAGE antibody ( $1 \mu \mathrm{g} / \mathrm{mL}$, solid square). B : MTT reduction was measured after $48 \mathrm{hr}$ incubation in media containing combinations of AGE, Vehicle (Veh), sildenafil citrate (SC, $20 \mu \mathrm{M})$, Rp-8-Br-cGMP $(\mathrm{RBcGMP}, 20 \mu \mathrm{M})$. Data were represented as the mean \pm SEM of 5 experiments. ${ }^{*} p<0.01$ vs. control, ${ }^{\dagger} p<0.01$ vs. Veh, ${ }^{\ddagger} p<0.01$ vs. SC.

cator of intact mitochondrial function. There was a time-dependent decrease in intracellular ATP content in AGE-treated cells. In 3 days, intracellular ATP concentration in AGE-treated cells decreased to lower than $25 \%$ of its control value. However, in cells pretreated with of anti-RAGE antibody AGE failed to inhibit ATP production (Fig. 2A). Sildenafil significantly reversed the AGE-induced inhibition of ATP generation. In the presence of Rp-8-Br-cGMP the protective effect of sildenafil was significantly diminished (Fig. 2B).

\section{Effect on ROS production}

Oxidative stress has been implicated in the AGE-induced neu-
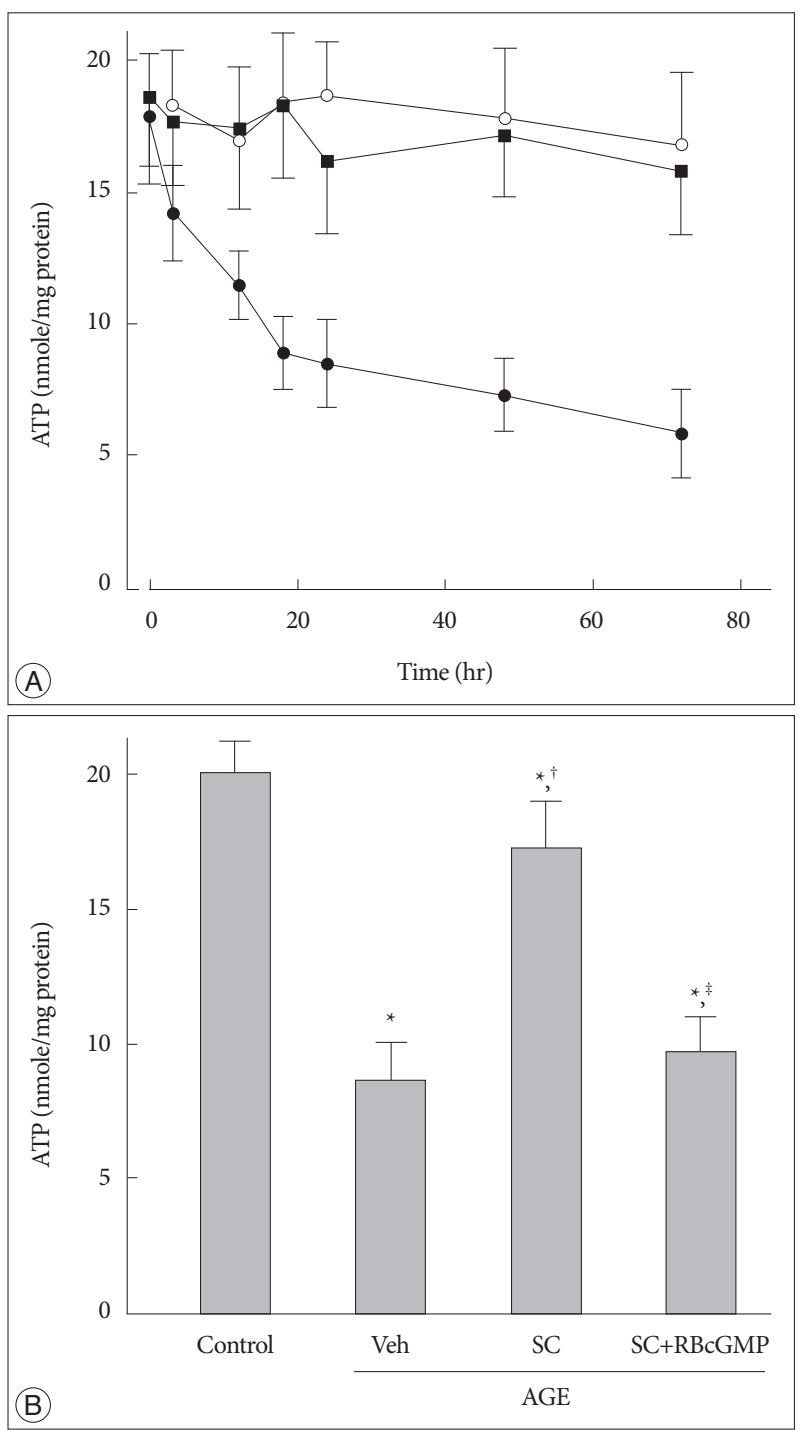

Fig. 2. Effect of sildenafil on cellular ATP content in AGE-treated cells. A : Cells were incubated for indicated time periods in control media with BSA (open circle), in the presence of AGE alone ( $200 \mu \mathrm{g} / \mathrm{mL}$, closed circle), or AGE with anti-RAGE antibody ( $1 \mu \mathrm{g} / \mathrm{mL}$, solid square). B : Cellular ATP was measured after $48 \mathrm{hr}$ incubation in media containing combinations of AGE, vehicle (Veh), sildenafil citrate (SC, $20 \mu \mathrm{M})$, Rp-8-Br-cGMP (RBcGMP, $20 \mu \mathrm{M})$. Data were represented as the mean \pm SEM of 6 experiments. ${ }^{*} p<0.01$ vs. control, ${ }^{\dagger} p<0.01$ vs. Veh, ${ }^{\ddagger} p<0.01$ vs. SC.

rotoxicity.

Thus to examine whether the protective effect of sildenafil against AGE-induced mitochondrial damage is associated with its effect on oxidative stress, we assessed the changes in ROS generation in AGE-treated cells in the presence and absence of sildenafil. After 30 min incubation with AGE, there was a remarkable increase in ROS formation, which was significantly suppressed in the presence of Rp-8-Br-cGMP (Fig. 3).

\section{Changes in mitochondrial membrane potential}

Disruption of the inner mitochondrial membrane potential associated with formation of permeability transition pore is a 
major event to initiate mitochondria-dependent apoptotic signaling ${ }^{21)}$. Therefore, it was examined whether AGE-induced mitochondrial dysfunction is associated with the disruption of mitochondrial membrane potential. Fig. 4A, B represents flow cytometric analysis of $\mathrm{DiOC}_{6}(3)$-stained cells. In these graphs left shift of cell population from strong (designated as M2) to weak
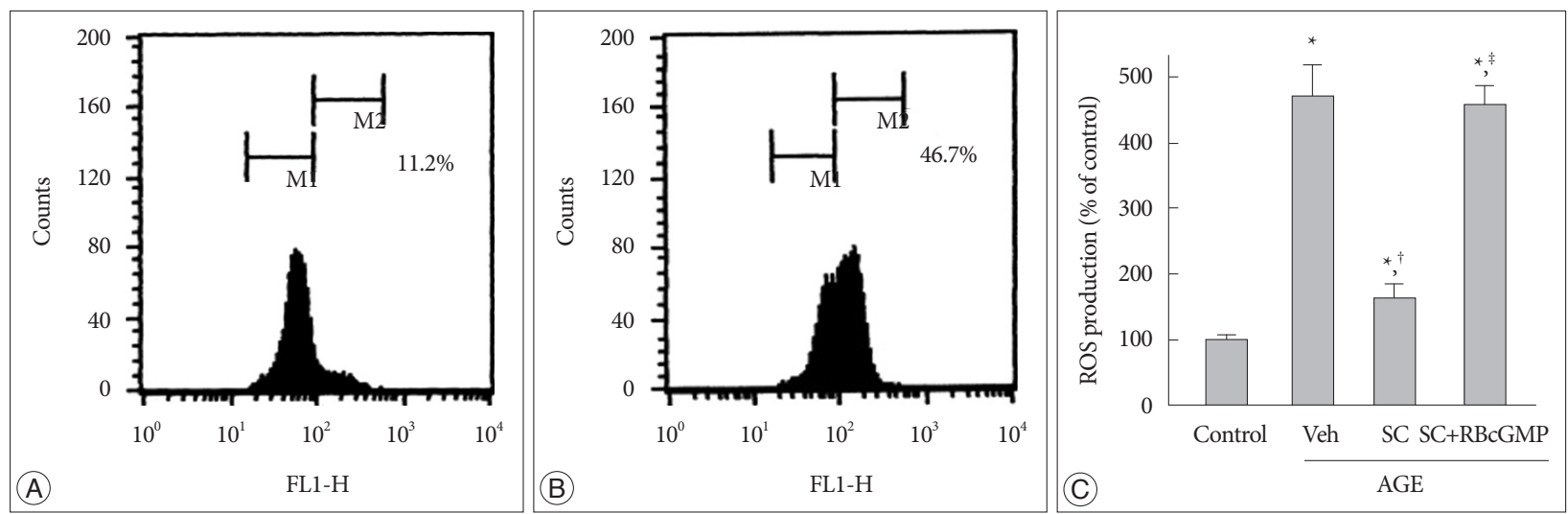

Fig. 3. Effect of sildenafil on ROS generation in AGE-treated cells. Flow cytometric analysis of DCFH-DA-loaded cells. A : Control. B : AGE-treated. C : ROS formation was measured by flow cytometric analysis of DCF fluorescence after $48 \mathrm{hr}$ incubation in media containing combinations of AGE, vehicle (Veh), sildenafil citrate (SC, $20 \mu \mathrm{M})$, Rp-8-Br-cGMP (RBcGMP, $20 \mu \mathrm{M})$. Data were represented as the mean \pm SEM of 5 experiments. ${ }^{*} p<0.01$ vs. control, ${ }^{\dagger} p<0.01$ vs. Veh, ${ }^{\ddagger} p<0.01$ vs. SC.
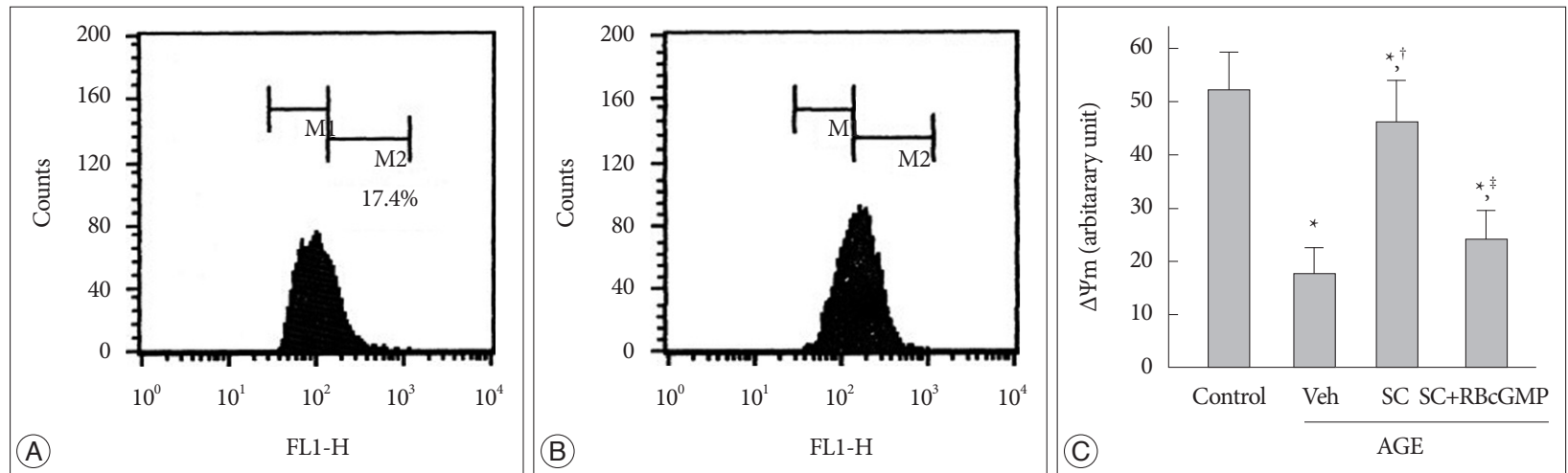

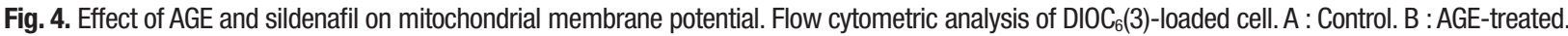
$C$ : Flow cytometric analysis was performed after $48 \mathrm{hr}$ incubation in media containing combinations of AGE, vehicle (Veh), sildenafil citrate (SC, $20 \mu \mathrm{M})$, Rp-8-Br-cGMP (RBcGMP, $20 \mu \mathrm{M})$. Data were represented as the mean \pm SEM of 6 experiments. ${ }^{\star} p<0.01$ vs. control, ${ }^{\dagger} p<0.01$ vs. Veh, ${ }^{\ddagger} p<0.01$ vs. SC.
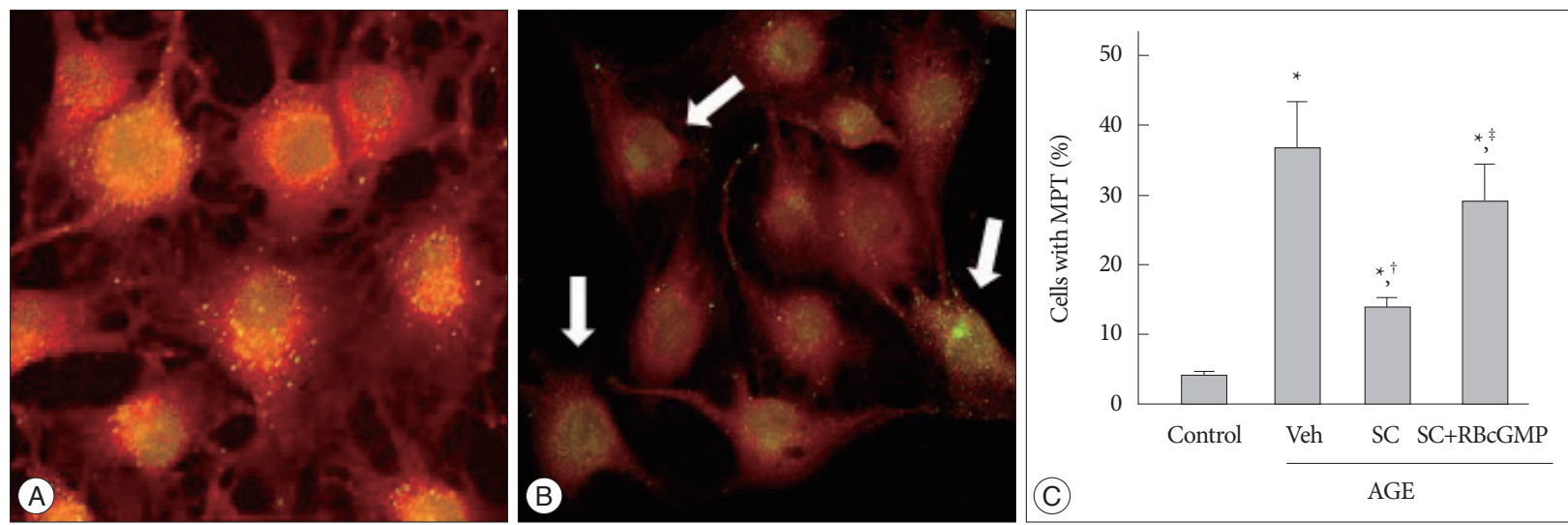

Fig. 5. Effect of sildenafil on mitochondrial permeability transition in AGE-treated cells. A and B : Confocal microscopic images showing cells with intact mitochondria and cells with mitochondrial permeability transition. Intact mitochondria accumulate TMR and are discriminated as punctuated bright red spots, whereas mitochondria undergoing MPT get deprived of TMR, became permeable to calcein, and as a consequence, loose their visible contour. Arrows indicate cells undergoing MPT. C : Confocal microscopic analysis was performed after $48 \mathrm{hr}$ incubation in media containing combinations of AGE, vehicle (Veh), sildenafil citrate (SC, $20 \mu \mathrm{M})$, Rp-8-Br-cGMP (RBcGMP, $20 \mu \mathrm{M})$. Data were represented as the mean \pm SEM of 6 experiments. ${ }^{*} p<0.01$ vs. control, ${ }^{\dagger} p<0.01$ vs. Veh, ${ }^{\ddagger} p<0.01$ vs. SC. 
(designated to $\mathrm{M} 1$ ) $\mathrm{DiOC}_{6}(3)$ fluorescence region indicates depolarization of inner mitochondrial membrane potential. The results showed that AGE depolarized the inner mitochondrial membrane potential. Sildenafil significantly reversed the AGEinduced disruption of the mitochondrial membrane potential. In the presence of Rp-8-Br-cGMP the effect of sildenafil was significantly diminished (Fig. 4C).

\section{AGE-induced MPT and its protection by sildenafil}

In confocal micrographs represented in Fig. 5A, B, intact mitochondria accumulated TMR and were discriminated as punctuated bright red spots, whereas injured mitochondria undergoing MPT got deprived of TMR, became permeable to calcein, and as a consequence, loose their visible contour. After $48 \mathrm{hr}$ incubation with AGE, there was a remarkable increase in cells with MPT, and sildenafil significantly suppressed it. In the presence of $\mathrm{Rp}-8$-Br-cGMP the effect of sildenafil was significantly attenuated (Fig. 5C).

\section{Cytochrome $\mathrm{C}$ release, caspase activation, and apoptosis}

Cytochrome $\mathrm{C}$ was detected by western blot analysis of the cytosolic fraction from cells treated with AGE for various time periods. In AGE-treated cells cytosolic release of cytochrome C increased significantly in a time-dependent manner, and sildenafil suppressed it (Fig. 6).

Activation of caspase cascades is critical for the execution phase of apoptosis. Caspase- 9 is activated by cytochrome $\mathrm{C}$ released from mitochondria and thus crucial for the execution of the mitochondria-dependent apoptosis, which in turn activates caspase-3. In AGE-treated cells, 4.1 fold increase in caspase- 3 activity was observed (Fig. 7A). In micrographs of cells stained with Hoechst-33258 represented in Fig. 7B, C, apoptotic cells are characterized by nuclear condensation and fragmentation. In paral- lel with caspase- 3 activation there was a significant increase in apoptotic cell number $(6.1 \pm 1.2 \%$ to $37.2 \pm 7.1 \%$ of total cell population). Sildenafil significantly suppressed both the AGE-induced caspasse-3 activation and apoptosis (Fig. 7D).

\section{Increased H0-1 expression by sildenafil}

Several investigators reported that sildenafil increased heme oxygenase-1 (HO-1) expression and it might play a role in the action of sildenafil ${ }^{1-3,18,22)}$. Hence, we examined whether sildenafil has any influence the HO-1 expression. qRT-PCR and Western blot analyses revealed that sildenafil significantly increased expression of both the HO-1 mRNA (Fig. 8A) and protein (Fig. 8B, C).

\section{Effects of $\mathrm{H0}-1$ related molecules}

In order to evaluate whether the effect of sildenafil resulted from the promoted expression of $\mathrm{HO}-1$, effects of $\mathrm{HO}-1$ related molecules were examined. Cobalt protophorphyrin (CoPP), an inducer of HO-1 inducer ${ }^{24)}$, and bilirubin, the metabolic product of $\mathrm{HO}-1^{24)}$, restored the AGE-induced decrease in MTT reduction ability. On the contrary zinc protoporphyrin IX (ZnPP IX), a HO-1 inhibitor ${ }^{24)}$ significantly diminished the effect of sildenafil (Fig. 9A). Similar results were observed in the experiments to examine the effects on the AGE-induced MPT (Fig. 9B). Overall, these results strongly indicate that sildenafil-induced protective effects are closely related with the increased expression of the HO-1.

\section{Effect of H0-1 siRNA transfection}

In order to confirm further the role of $\mathrm{HO}-1$, we used cells transfected with siRNA. In cells transfected with the HO-1 siRNA the basal expression of the HO-1 protein was significantly diminished. In these cells, CoPP and sildenafil had no influence on the HO-1 expression (Fig. 10A). Likewise, in siRNA-trans-
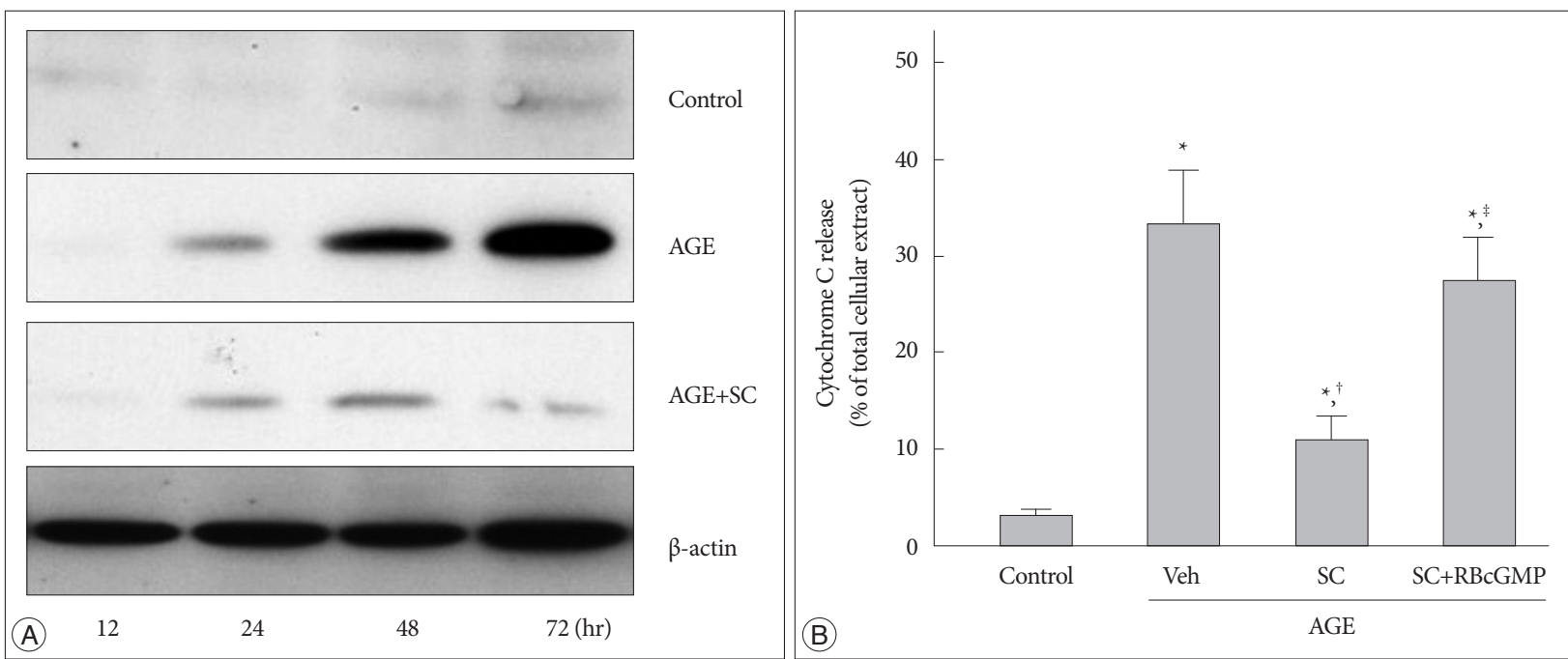

Fig. 6. Effect of sildenafil on cytochrome $C$ release in AGE-treated cells. A : Western blot analysis was performed for cytosolic released cytochrome $C$ after incubation for indicated time periods in control media with BSA, in the presence of AGE ( $200 \mu \mathrm{g} / \mathrm{mL}$, closed circle), or AGE with sildenafil (SC, $20 \mu \mathrm{M})$. B : Western blot analysis was performed after $48 \mathrm{hr}$ incubation in media containing combinations of AGE, vehicle (Veh), sildenafil citrate (SC, $20 \mu \mathrm{M})$, $\mathrm{Rp}-8$-Br-cGMP (RBcGMP, $20 \mu \mathrm{M})$. Data were represented as the mean \pm SEM of 6 experiments. ${ }^{\star} p<0.01$ vs. control, ${ }^{\dagger} p<0.01 \mathrm{vs}$. Veh, ${ }^{\ddagger} p<0.01 \mathrm{vs}$. SC. 

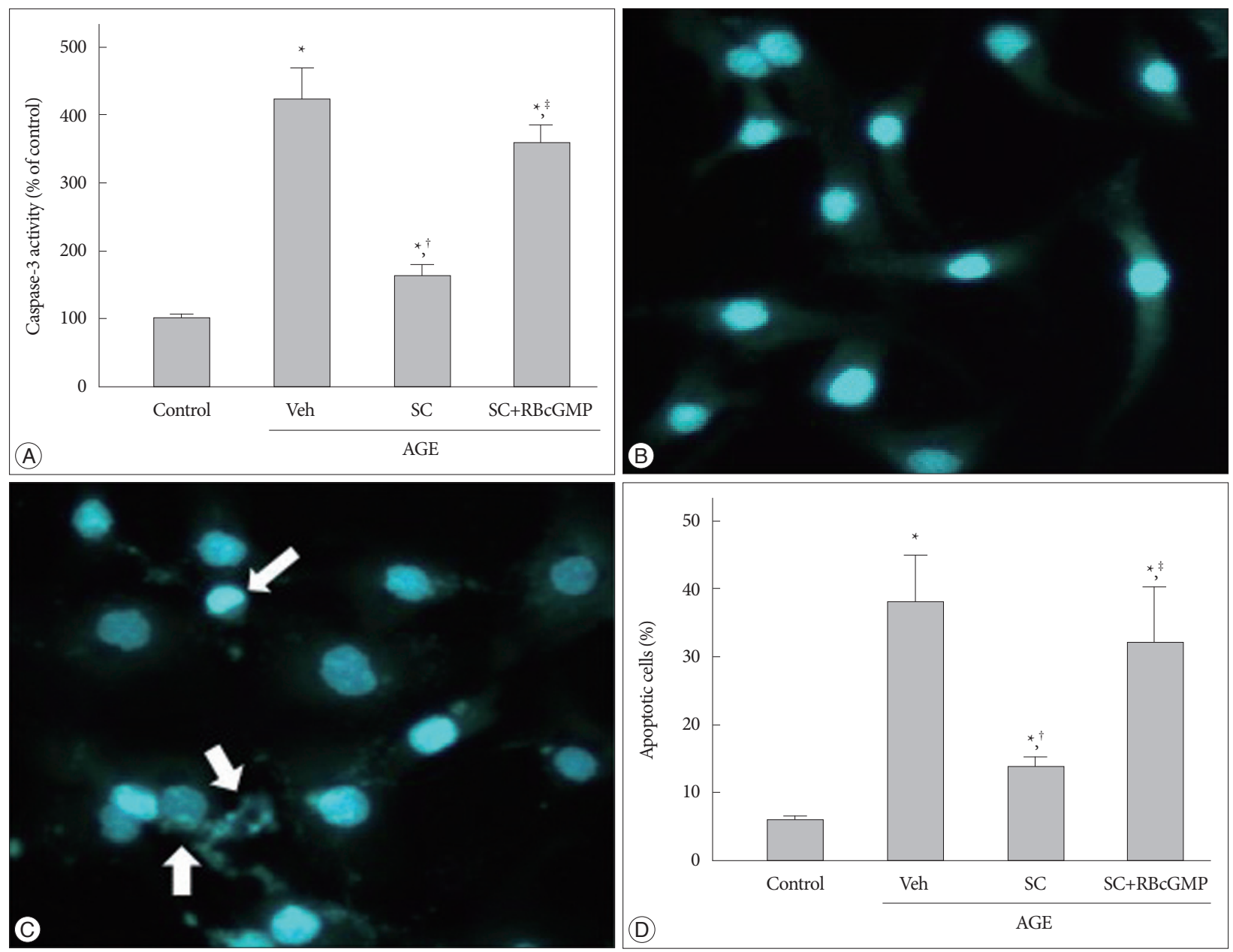

Fig. 7. Effect of sildenafil on apoptosis in AGE-treated cells. A : Representative micrographs of Hoechst-33258-stained cells. Arrows indicate apoptotic cells. B : Apoptosis was analyzed by staining with Hoechst-33258 after $48 \mathrm{hr}$ incubation in media containing combinations of AGE, vehicle (Veh), sildenafil citrate (SC, $20 \mu \mathrm{M})$, Rp-8-Br-cGMP (RBcGMP, $20 \mu \mathrm{M})$. Data were represented as the mean \pm SEM of 6 experiments. ${ }^{*} p<0.01$ vs. control, ${ }^{\dagger} p<0.01$ vs. Veh, ${ }^{\ddagger} p<0.01$ vs. SC.
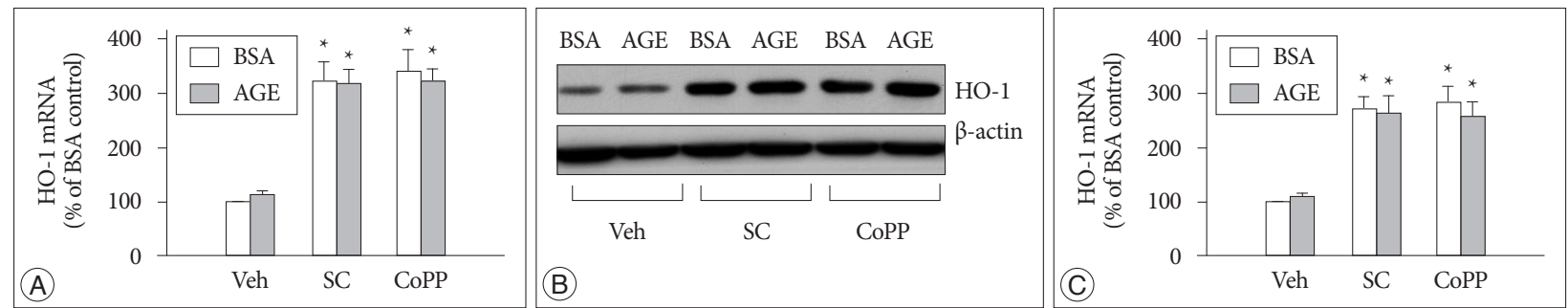

Fig. 8. Increased H0-1 expression by sildenafil. Cells were incubated for $48 \mathrm{hr}$ in the presence of each $200 \mu \mathrm{g} / \mathrm{mL}$ of control BSA or AGE with vehicle (DMSO, Veh), $20 \mu \mathrm{M}$ sildenafil citrate (SC) and $20 \mu \mathrm{M}$ cobalt protophorphyrin (CoPP). A : H0-1 mRNA was determined by qRT-PCR. B and C : H0-1 protein was determined by Western blot analysis. Data were represented as the mean \pm SEM of 4 experiments. ${ }^{*} p<0.01$ vs. Veh.

fected cells, sildenafil failed to restore the AGE-induced changes in MTT reduction ability and MPT induction (Fig. 10B, C). These results further support our hypothesis that promoted expression of HO-1 is closely related with the sildenafil-induced protection mechanism.

\section{DISCUSSION}

AGE has been known to play an important role in the patho- genesis of neurodegenerative disorders including diabetic encephalopathy, aging changes, and Alzheimer disease $(\mathrm{AD})^{11,40)}$. AGE were detected in the cytosol of neurons in the hippocampus and para-hippocampal gyrus of human $\mathrm{AD}$ brains ${ }^{44)}$. Moreover, AGE disrupted the blood-brain barrier in brain microvascular endothelium under diabetic conditions ${ }^{42)}$, further confirming us the critical role of AGE in diabetic encephalopathy.

Diabetic encephalopathy is characterized by cognitive deficits and neuropathology ${ }^{19,25,43)}$. Neuropathology is associated 

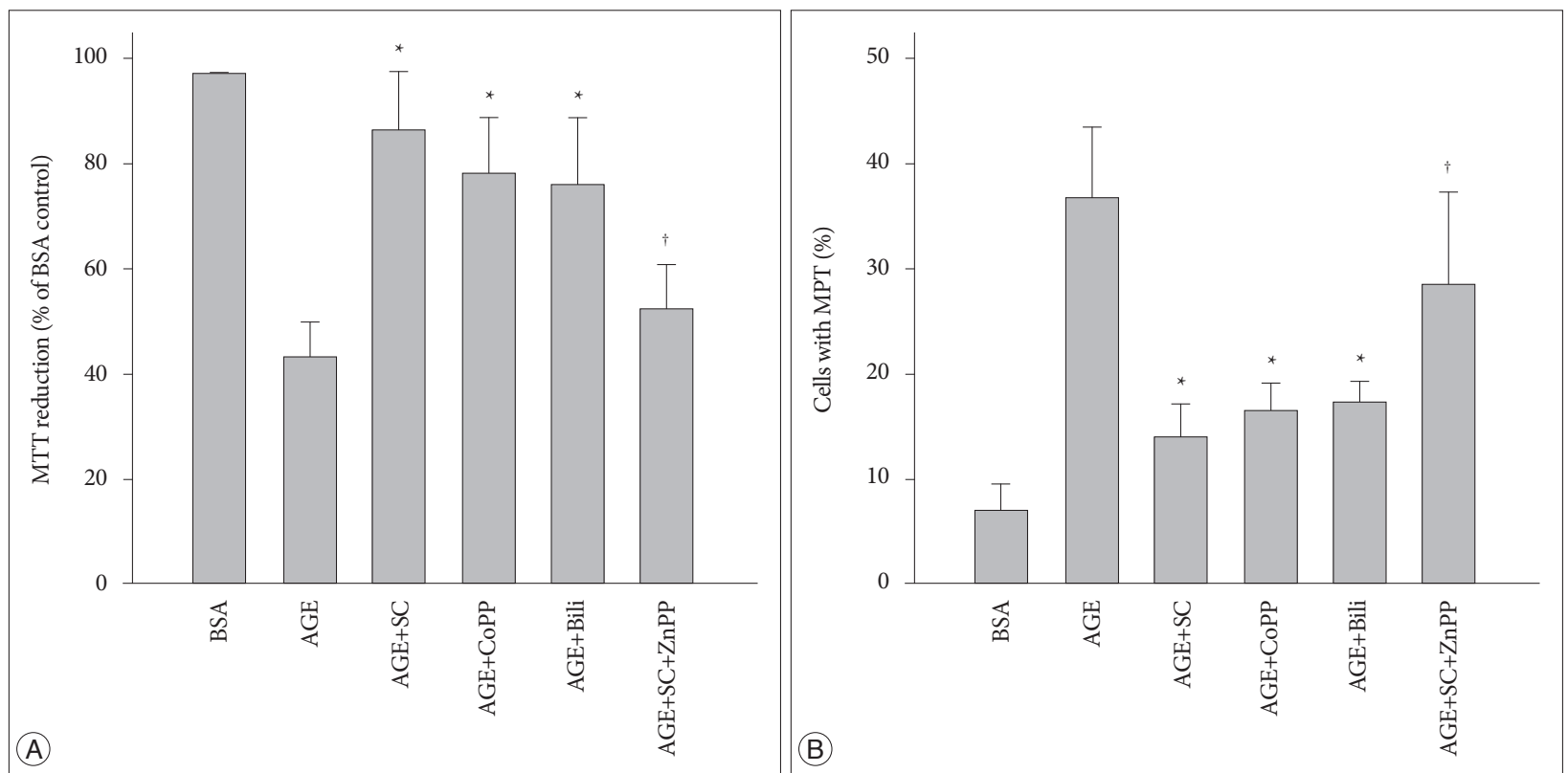

Fig. 9. Effects of HO-1 related agents on AGE-induced changes in MTT reduction and MPT induction. Cells were incubated in the presence of each $200 \mu \mathrm{g} / \mathrm{mL}$ of control BSA or AGE-BSA (AGE) for $24 \mathrm{hr}$ with or without each $20 \mu \mathrm{M}$ of sildenafil citrate (SC), cobalt protophorphyrin (CoPP), bilirubin (Bili), and zinc protoporphyrin IX (ZnPP). A : MTT reduction was determined by colorimetric analysis of formazan. B : Confocal microscopic analysis was performed in cells double-stained with TMRM and calcein/AM. Data were represented as the mean \pm SEM of 4 experiments. ${ }^{*} p<0.01$ vs. control, ${ }^{\dagger} p<0.01$ vs. AGE + SC.
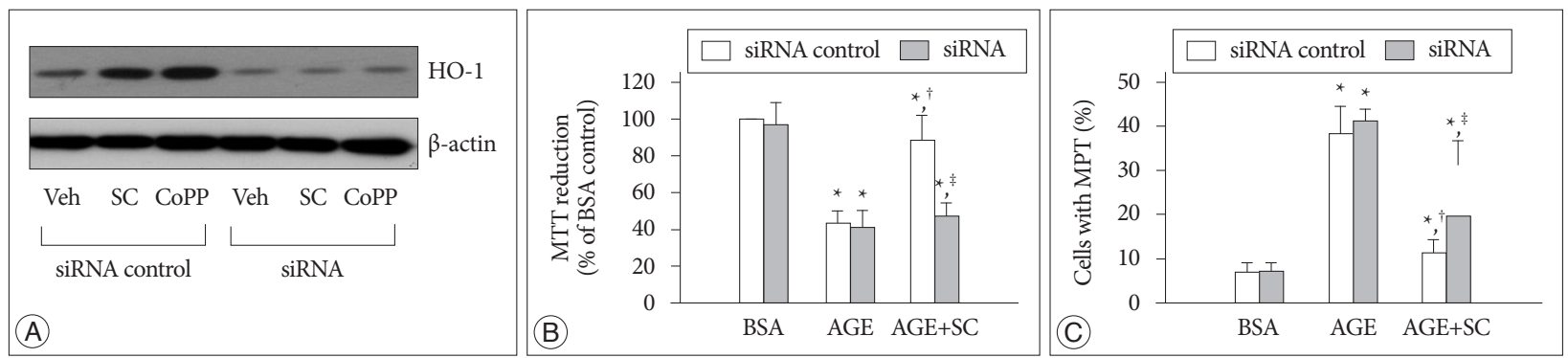

Fig. 10. A : Effect of siRNA transfection on H0-1 protein expression. Cells were transfected with 30 picomoles of H0-1 siRNA or scrambled siRNA (siRNA control) and incubated for $24 \mathrm{hr}$ with vehicle (Veh) or each $20 \mu \mathrm{M}$ of sildenafil citrate (SC) and cobalt protophorphyrin (CoPP). H0-1 protein was determined by Western blot analysis of the cell extracts. B : MTT reduction was determined by colorimetric analysis. C : Confocal microscopic analysis was performed in cells double-stained with TMRM and calcein/AM. Data were represented as the mean \pm SEM of 4 experiments. ${ }^{\star} p<0.01$ vs. BSA control, ${ }^{\dagger} p<0.01$ vs. AGE alone, ${ }^{\ddagger} p<0.01$ vs. siRNA control.

with multiple lesions including reduced ATP synthesis and altered mitochondrial structure and function ${ }^{4,40)}$. Deterioration of mitochondrial membrane potential, induction of MPT and subsequent release of cytochrome $\mathrm{C}$ through this MPT pore ${ }^{21)}$ are known to be initial events. Released cytochrome $\mathrm{C}$ activates caspase cascades, which are critical for the execution phase of apoptosis.

The present study provided evidence that AGE deteriorates mitochondrial functional integrity in HT-22 neuronal cells. AGE inhibited MTT reduction (Fig. 1) and cellular ATP production (Fig. 2), and stimulated intracellular ROS production (Fig. 3) in the HT-22 neuronal cells. It also caused deterioration of mitochondrial membrane potential (Fig. 4), and substantial cytochrome $\mathrm{C}$ release from the mitochondria to the cytosol (Fig. 6) and activation of caspase 3 which was accompanied by apoptosis (Fig. 7). Double fluorescence imaging studies with TMRM and calcein/AM demonstrated the release of cytochrome $\mathrm{C}$ is a consequence of MPT. These findings suggest that mitochondrial dysfunction may be a crucial event to cause AGE-induced neuropathy in the HT-22 neuronal cells.

RAGE, AGE-R3 (galectin-3), and maybe other AGE-binding proteins mediate the AGE-induced cellular effects. Among them, RAGE is the best characterized AGE receptor which is responsible for most of the detrimental effects of $\mathrm{AGE}^{41)}$. In cells pretreated with anti-RAGE antibody, AGE did not affect the MTT reduction ability and cellular ATP generation suggesting that AGE-RAGE interaction is crucial for the cellular actions of AGE (Fig. 1A, 2A).

Apart from its efficacy in erectile dysfunction and pulmonary hypertension, the potential application of sildenafil in many experimental models of diseases has been indicated. In terms of the brain, several lines of studies have suggested that sildenafil 
might provide beneficial effects to prevent the brain dysfunction and pathological changes associated with aging and $\mathrm{AD}$. Sildenafil prevented the decline of cognitive performance, and in addition, the increase in $\mathrm{A} \beta$ levels of $\mathrm{AD}$ mice ${ }^{37)}$. It reverted the shifting of amyloid precursor protein processing toward $\mathrm{A} \beta 42$ production and the increase of the $A \beta 42$ : $A \beta 40$ ratio in physiological mouse model of aging suggesting that PDE-5 inhibitor might be beneficial to treat the age-related brain pathologies ${ }^{36)}$.

The present study provided clear evidence that sildenafil provide beneficial effect to protect mitochondria from AGE-induced injuries. It helped mitochondria to preserve the ability to reduce MTT (Fig. 1) and produce ATP (Fig. 2) in these cells. Furthermore, it prevented cascades of event which lead to apoptotic cell death, deterioration of mitochondrial membrane potential (Fig. 4), induction of MPT (Fig. 5), cytochrome C release (Fig. 6), and activation of caspase 3 which was accompanied by apoptosis (Fig. 7) in AGE-treated cells. These results strongly suggests that sildenafil provides a beneficial effect to protect the mitochondria against AGE-induced irreversible damages.

Enhancement of the HO-1 pathway has been proven to be a potential tool to protect neurons from oxidative injuries ${ }^{8)}$. HO-1 produces carbon monoxide $(\mathrm{CO})$ and bilirubin as products of heme metabolism. Bilirubin acts as a strong antioxidant ${ }^{29,30)}$. As generation of ROS has been known to play a crucial role in varied forms of diabetic encephalopathies, increased bilirubin production could provide helpful effects to decrease oxidative injuries.

In the present study, it was strongly suggested that HO-1 is involved in sildenafil-induced prevention of AGE-induced mitochondrial dysfunction. In qRT-PCR and Western blot analyses, it was demonstrated that sildenafil promoted the HO- 1 expression (Fig. 8). CoPP, a HO-1 inducer ${ }^{24)}$ and bilirubin, the metabolic product of $\mathrm{HO}-\mathrm{1}^{24)}$ showed a similar protective effects. On the contrary, in cells treated with ZnPP IX, a HO-1 inhibitor ${ }^{24)}$, the effect of sildenafil was significantly attenuated (Fig. 9). Transfection with small interfering RNA confirm further confirmed the involvement of HO-1 in the action mechanism of sildenafil (Fig. 10).

The findings in this study provides us with valuable informations for understanding the pharmacological efficacy of sildenafil which may expand the area of its therapeutic use beyond for the treatment of erectile dysfunction and pulmonary hypertension. Sildenafil is one of the most frequently prescribed drug for the men with erectile dysfunction associated with DM. It has been proven safe even for prolonged treatment. Furthermore, it is worthwhile to note several recent reports which described the beneficial effect of continuous daily sildenafil treatment to promote endothelial function ${ }^{6,20)}$.

\section{CONCLUSION}

Therefore, if PDE-5 inhibitors, such as sildenafil, could provide beneficial effects to ameliorate $\mathrm{AD}$ - or $\mathrm{DM}$-associated pathogenic processes they could be considered as a potential therapeutic agents for AD-, DM-, and aging-associated brain dysfunction and encephalopathies.

\section{- Acknowledgements}

This study was supported by Research Institute for Convergence of biomedical science and technology Grant (30-2013-007), Pusan National University Yangsan Hospital.

\section{References}

1. Abdel Aziz MT, El-Asmer MF, Mostafa T, Mostafa S, Atta H, Aziz Wassef MA, et al. : Heme oxygenase vs. nitric oxide synthase in signaling mediating sildenafil citrate action. J Sex Med 4 (4 Pt 2) : 1098-1107, 2007

2. Aziz MT, Al-Asmar MF, Mostafa T, Atta H, Rashed L, Sabry D, et al. : Assessment of heme oxygenase-1 (HO-1) activity in the cavernous tissues of sildenafil citrate-treated rats. Asian J Androl 9: 377-381, 2007

3. Aziz MT, Mostafa T, Atta H, Rashed L, Marzouk SA, Obaia EM, et al. : The role of PDE5 inhibitors in heme oxygenase-cGMP relationship in rat cavernous tissues. J Sex Med 5 : 1636-1645, 2008

4. Beal MF : Mitochondrial dysfunction in neurodegenerative diseases. Biochim Biophys Acta 1366 : 211-223, 1998

5. Brownlee $\mathrm{M}$ : Biochemistry and molecular cell biology of diabetic complications. Nature 414 : 813-820, 2001

6. Burnett AL, Strong TD, Trock BJ, Jin L, Bivalacqua TJ, Musicki B : Serum biomarker measurements of endothelial function and oxidative stress after daily dosing of sildenafil in type 2 diabetic men with erectile dysfunction. J Urol $181: 245-251,2009$

7. Cadirci E, Halici Z, Odabasoglu F, Albayrak A, Karakus E, Unal D, et al. : Sildenafil treatment attenuates lung and kidney injury due to overproduction of oxidant activity in a rat model of sepsis : a biochemical and histopathological study. Clin Exp Immunol 166 : 374-384, 2011

8. Chen J : Heme oxygenase in neuroprotection : from mechanisms to therapeutic implications. Rev Neurosci $25: 269-280,2014$

9. Choei H, Sasaki N, Takeuchi M, Yoshida T, Ukai W, Yamagishi S, et al. : Glyceraldehyde-derived advanced glycation end products in Alzheimer's disease. Acta Neuropathol 108 : 189-193, 2004

10. Choi DE, Jeong JY, Lim BJ, Chung S, Chang YK, Lee SJ, et al. : Pretreatment of sildenafil attenuates ischemia-reperfusion renal injury in rats. Am J Physiol Renal Physiol 297 : F362-F370, 2009

11. Dar TA, Sheikh IA, Ganie SA, Ali R, Singh LR, Gan SH, et al. : Molecular linkages between diabetes and Alzheimer's disease : current scenario and future prospects. CNS Neurol Disord Drug Targets $13: 290-298$, 2014

12. Gaens KH, Stehouwer CD, Schalkwijk CG : Advanced glycation endproducts and its receptor for advanced glycation endproducts in obesity. Curr Opin Lipidol 24 : 4-11, 2013

13. Ghofrani HA, Osterloh IH, Grimminger F : Sildenafil : from angina to erectile dysfunction to pulmonary hypertension and beyond. Nat Rev Drug Discov 5 : 689-702, 2006

14. Hotston MR, Jeremy JY, Bloor J, Koupparis A, Persad R, Shukla N : Sildenafil inhibits the up-regulation of phosphodiesterase type 5 elicited with nicotine and tumour necrosis factor-alpha in cavernosal vascular smooth muscle cells : mediation by superoxide. BJU Int 99 : 612-618, 2007

15. IDF Diabetes Atlas Group : Update of mortality attributable to diabetes for the IDF Diabetes Atlas : estimates for the year 2011. Diabetes Res Clin Pract $100: 277-279,2013$

16. Jackson G, Gillies H, Osterloh I : Past, present, and future : a 7-year update of Viagra (sildenafil citrate). Int J Clin Pract 59: 680-691, 2005

17. Jeremy JY, Koupparis A, Muzaffar S, Persad R, Angelini GD, Shukla N : Is the therapeutic action of sildenafil mediated partly through the inhibition of superoxide formation? BJU Int 95 : 930-931, 2005

18. Kawahara G, Gasperini MJ, Myers JA, Widrick JJ, Eran A, Serafini PR, et al. : Dystrophic muscle improvement in zebrafish via increased heme 
oxygenase signaling. Hum Mol Genet 23 : 1869-1878, 2014

19. Kodl CT, Seaquist ER : Cognitive dysfunction and diabetes mellitus. Endocr Rev 29: 494-511, 2008

20. Konstantinopoulos A, Giannitsas K, Athanasopoulos A, Spathas D, Perimenis P : The impact of daily sildenafil on levels of soluble molecular markers of endothelial function in plasma in patients with erectile dysfunction. Expert Opin Pharmacother 10 : 155-160, 2009

21. Lemasters JJ, Nieminen AL, Qian T, Trost LC, Elmore SP, Nishimura Y, et al. : The mitochondrial permeability transition in cell death : a common mechanism in necrosis, apoptosis and autophagy. Biochim Biophys Acta 1366 : 177-196, 1998

22. Liu XM, Peyton KJ, Wang X, Durante W : Sildenafil stimulates the expression of gaseous monoxide-generating enzymes in vascular smooth muscle cells via distinct signaling pathways. Biochem Pharmacol 84 : 1045-1054, 2012

23. Lyman GE, DeVincenzo JP : Determination of picogram amounts of ATP using the luciferin-luciferase enzyme system. Anal Biochem 21 : 435-443, 1967

24. Marks GS : Heme oxygenase : the physiological role of one of its metabolites, carbon monoxide and interactions with zinc protoporphyrin, cobalt protoporphyrin and other metalloporphyrins. Cell Mol Biol (Noisyle-grand) $40: 863-870,1994$

25. Mijnhout GS, Scheltens P, Diamant M, Biessels GJ, Wessels AM, Simsek $S$, et al. : Diabetic encephalopathy : a concept in need of a definition. Diabetologia 49: 1447-1448, 2006

26. Morgan DM : Tetrazolium (MTT) assay for cellular viability and activity. Methods Mol Biol 79 : 179-183, 1998

27. Muzaffar S, Shukla N, Jeremy JY : Nicotinamide adenine dinucleotide phosphate oxidase : a promiscuous therapeutic target for cardiovascular drugs? Trends Cardiovasc Med 15 : 278-282, 2005

28. Negi G, Kumar A, Kaundal RK, Gulati A, Sharma SS : Functional and biochemical evidence indicating beneficial effect of Melatonin and Nicotinamide alone and in combination in experimental diabetic neuropathy. Neuropharmacology $58: 585-592,2010$

29. Neuzil J, Stocker R : Bilirubin attenuates radical-mediated damage to serum albumin. FEBS Lett $331: 281-284,1993$

30. Neuzil J, Stocker R : Free and albumin-bound bilirubin are efficient coantioxidants for alpha-tocopherol, inhibiting plasma and low density lipoprotein lipid peroxidation. J Biol Chem 269 : 16712-16719, 1994

31. Oates PJ : Aldose reductase, still a compelling target for diabetic neuropathy. Curr Drug Targets 9: 14-36, 2008

32. Piperi C, Adamopoulos C, Dalagiorgou G, Diamanti-Kandarakis E, Papavassiliou AG : Crosstalk between advanced glycation and endoplasmic reticulum stress : emerging therapeutic targeting for metabolic dis- eases. J Clin Endocrinol Metab 97 : 2231-2242, 2012

33. Pop-Busui R, Marinescu V, Van Huysen C, Li F, Sullivan K, Greene DA, et al. : Dissection of metabolic, vascular, and nerve conduction interrelationships in experimental diabetic neuropathy by cyclooxygenase inhibition and acetyl-L-carnitine administration. Diabetes $51: 2619-2628$, 2002

34. Pun PB, Murphy MP : Pathological significance of mitochondrial glycation. Int J Cell Biol 2012 : 843505, 2012

35. Purves T, Middlemas A, Agthong S, Jude EB, Boulton AJ, Fernyhough P, et al. : A role for mitogen-activated protein kinases in the etiology of diabetic neuropathy. FASEB J 15 : 2508-2514, 2001

36. Puzzo D, Loreto C, Giunta S, Musumeci G, Frasca G, Podda MV, et al. : Effect of phosphodiesterase-5 inhibition on apoptosis and beta amyloid load in aged mice. Neurobiol Aging 35 : 520-531, 2014

37. Puzzo D, Staniszewski A, Deng SX, Privitera L, Leznik E, Liu S, et al. : Phosphodiesterase 5 inhibition improves synaptic function, memory, and amyloid-beta load in an Alzheimer's disease mouse model. J Neurosci $29: 8075-8086,2009$

38. Rashid A : The efficacy and safety of PDE5 inhibitors. Clin Cornerstone $7: 47-56,2005$

39. Rolo AP, Palmeira CM : Diabetes and mitochondrial function : role of hyperglycemia and oxidative stress. Toxicol Appl Pharmacol 212 : 167178,2006

40. Sandireddy R, Yerra VG, Areti A, Komirishetty P, Kumar A : Neuroinflammation and oxidative stress in diabetic neuropathy : futuristic strategies based on these targets. Int J Endocrinol 2014 : 674987, 2014

41. Schmidt AM, Yan SD, Yan SF, Stern DM : The biology of the receptor for advanced glycation end products and its ligands. Biochim Biophys Acta 1498 : 99-111, 2000

42. Shimizu F, Sano Y, Tominaga O, Maeda T, Abe MA, Kanda T: Advanced glycation end-products disrupt the blood-brain barrier by stimulating the release of transforming growth factor- $\beta$ by pericytes and vascular endothelial growth factor and matrix metalloproteinase- 2 by endothelial cells in vitro. Neurobiol Aging $34: 1902-1912,2013$

43. Sima AA : Encephalopathies : the emerging diabetic complications. Acta Diabetol $47: 279-293,2010$

44. Takeuchi M, Yamagishi S : Possible involvement of advanced glycation end-products (AGEs) in the pathogenesis of Alzheimer's disease. Curr Pharm Des 14 : 973-978, 2008

45. Vlassara $\mathrm{H}$, Striker GE : AGE restriction in diabetes mellitus : a paradigm shift. Nat Rev Endocrinol 7 : 526-539, 2011

46. Yu T, Robotham JL, Yoon Y : Increased production of reactive oxygen species in hyperglycemic conditions requires dynamic change of mitochondrial morphology. Proc Natl Acad Sci U S A 103 : 2653-2658, 2006 